\title{
Influences of Continuous Rotation and TF adaptive Motion on the Resistance of Different Retreatment File Systems to Deformation and Fracture: An In Vitro study
}

\author{
${ }^{1}$ Divya Meena, ${ }^{2}$ Ramyadharshini, ${ }^{3}$ Nivedha V, ${ }^{4}$ Anand Sherwood, ${ }^{5}$ Senthil Kumar
}

\begin{abstract}
Objectives: To determine the influence of TF adaptive motion on fatigue resistance and efficacy of gutta-percha removal by retreatment files.
\end{abstract}

Materials and methods: A total of 180 extracted single rooted natural human lower premolar teeth were used. Root canal preparations were completed using Mtwo files and obturated using a thermoplastic technique. The teeth were randomly divided into six groups. Three different retreatment file systems (D race, ProTaper universal retreatment, and TF adaptive files) employed with two different rotary motion of continuous and TF adaptive motion. Efficacy of gutta-percha removal was estimated using radiograph and retreatment files were assessed for deformation or fracture using an operating microscope (1.6x and 2.5x magnification). Data were analyzed using analysis of variance (ANOVA) and Chi-square tests $(p<0.05)$ in Statistical Package for the Social Sciences (SPSS) version 23.0.

Results: ProTaper retreatment files took significantly less time to reach working length. ProTaper retreatment files were able to delete gutta-percha from more number of samples. Both $D$ race and TF adaptive files exhibited fracture.

Conclusion: TF adaptive motion did not improve the performance of the retreatment files.

Keywords: Cyclic fatigue, Retreatment files, TF adaptive motion, Torsional fatigue.

How to cite this article: Meena D, Ramyadharshini, Nivedha V, Sherwood A, Kumar S. Influences of Continuous Rotation and TF adaptive Motion on the Resistance of different Retreatment file systems to Deformation and Fracture: An In Vitro study. J Oper Dent Endod 2018;3(2):71-78.

Source of support: Nil

Conflict of interest: None

\section{INTRODUCTION}

As clinicians, we are required to deal with root canal failures due to several reasons where endodontic retreat-

\footnotetext{
${ }^{1-3}$ Postgraduate Student, ${ }^{4}$ Professor and Head, ${ }^{5}$ Reader

${ }^{1-5}$ Department of Conservative Dentistry and Endodontics, CSI College of Dental Sciences, Madurai, Tamil Nadu, India
}

Corresponding Author: Divya Meena, Professor and Head, Department of Conservative Dentistry and Endodontics, CSI College of Dental Sciences, Madurai, Tamil Nadu, India, e-mail: anand.sherwood@gmail.com ment will have to be considered. ${ }^{1}$ In root canal retreatment one of the challenges will be complete removal of the obturated material which will significantly improve the clinical success of the treatment. Many different root canal obturating materials have been in use, but still, gutta-percha with sealer is the most popular choice. Techniques commonly employed for gutta-percha removal been stainless-steel hand files, nickel-titanium rotary files, heat-bearing instruments, ultrasonics, solvents. ${ }^{2}$

Rotary instrumentation has been recommended as the most efficient method for gutta-percha removal. ${ }^{2}$ Several different root canal retreatment systems are available in the market. Many studies has been conducted with these systems in continuous rotary, reciprocating and TF adaptive motions with results being inconclusive of one system and motion superior over another. ${ }^{3-8}$ A new concept in rotary file motion that has been introduced is TF adaptive. Sybron Endo introduced TF adaptive motion in 2013 which aims to combine the benefits of both rotary and reciprocating motions. In this motion when the instrument is not or minimally stressed the motion is a rotation of $600^{\circ}$ in the clockwise (CW) direction, a stop and then restart in the $\mathrm{CW}$ direction. When the instrument engages dentin or root filling the motion of the instrument becomes reciprocal due to the increased stress. ${ }^{9}$ The reciprocal angles are not constant and the motor modifies the clockwise/counter clockwise (CW/CCW) angles from $600 / 0^{\circ}$ to $370 / 50^{\circ}$, depending upon the stress on the instrument. ${ }^{9}$ This TF adaptive motion is an extension of a reciprocating motion introduced by Yared in 2008 based on a balanced force concept. ${ }^{10}$ Since most of the rotary files are designed for cutting in $\mathrm{CW}$ direction, thus allowing the adaptive motion to be used with most rotary files. ${ }^{9}$ Higher cyclic fatigue resistances have been reported for TF adaptive motion both for primary treatment and retreatment files. ${ }^{11,12}$

Only a few reports are examining the efficacy of $\mathrm{TF}$ adaptive files and motion for removal of root canal filling materials. ${ }^{12,13}$ Therefore, the present study aims to examine the influence of TF adaptive motion on fatigue resistance and efficacy of gutta-percha removal by retreatment nickel-titanium files in comparison to rotary motion. The null hypothesis is that there is no significant difference in the removal of root canal filling material and fatigue resistance among the techniques tested. 


\section{MATERIALS AND METHODS}

A total of 180 extracted single-rooted natural human lower premolar teeth were used; they were examined radiographically to verify single canal presence with patent apical foramen. Institutional ethical committee approval was obtained for the use of extracted human teeth. The specimens are stored in $0.1 \%$ thymol solution and incubated 48 hours before being used for the study. The teeth were sectioned at a cemento enamel junction and ensured the root length of all the specimens were 15 $\mathrm{mm}$ to make sure the entire length of the flutes of retreatment rotary files engage with gutta-percha. All the teeth were embedded in a self cure acrylic matrix (RR cold cure, dry-powder inhaler (DPI), Mumbai, India) to make sure the teeth remain in place during instrumentation of the canals.

\section{Canal Instrumentation}

Apical patencies of root canals were assessed by inserting a 15 size $\mathrm{K}$ file (Mani, Inc., Japan) $1 \mathrm{~mm}$ beyond apical foramen. Working length was estimated by subtracting $1 \mathrm{~mm}$ from the previously estimated length and verified using PSP scanner (VistaScan Mini Plus, Durr Dental., Germany). The root canals were prepared using the crown-down technique. Glide paths for canals were established till 25 size $\mathrm{K}$ file. Canal irrigation was done with $3 \%$ sodium hypochlorite (Septodont Healthcare Pvt ltd., India) using 24 gauge needle (Dispovan, India). Rotary nickel-titanium files Mtwo (VDW GmbH., Germany) 20 and 25 sizes with a taper of $6 \%$ were used according to manufacturer's instruction with EndoTouch TC2 (Kerr., California, United States of America) cordless endomotor. EDTA paste Endoprep-RC (Anabond Stedman Pharma Research Ltd, India) was used as a lubricating agent with a rotary file for canal preparation (Fig. 1A).

The root canals were dried using paper points after canal preparation. Master cone was verified with radiograph with size 25, 6\% gutta-percha (Dia Dent group, Seoul, Korea). Obturation was completed with 6\%, 25 size gutta-percha points (Dia Dent group, Seoul, Korea) by thermoplastic technique. Super endo alpha II (B \& L Biotech, Korea) for apical third obturation of the canal and Super endo beta (B \& L Biotech, Korea) was used as backfill for the remainder of canal obturation. The quality of canal obturation was verified using radiograph, and assessed for the presence of voids or gaps which necessitated a reworking of the canal and obturation (Fig. 1B).

\section{Root Canal Filling Removal}

The teeth were randomly divided into six groups. Three different retreatment file systems employed with two

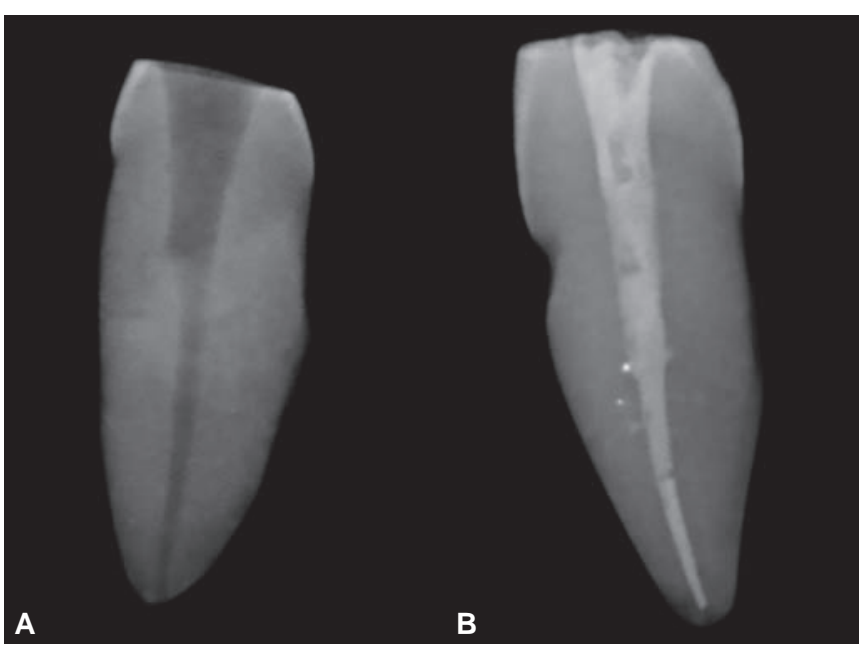

Figs 1A and B: (A) Radiograph of sample lower premolar after shaping of the root canal; (B) Radiograph of completed obturation of canal by thermoplastic technique

different rotary motion of continuous and TF adaptive motion.

Reinstrumentation of the canal was done only with rotary retreatment files no hand files were used. Once as each of rotary retreatment files in the sequence reaches the working length, a radiograph is taken to verify the efficacy of gutta-percha removal. Canal irrigation was done with saline (NS $500 \mathrm{~mL}$, Sodium Chloride 0.9\%, Fresenius Kabi, India Pvt. Ltd). Time taken in seconds for files to reach the working length and number of revolutions (rpm) is noted. Total of 4 minutes was allotted for gutta-percha removal from each tooth. Two sets of three different retreatment file systems were used with both continuous and TF adaptive motion in this study. Each retreatment file system in each rotary motion was used to a maximum 30 number of teeth or till one of the files in the sequence fractures. Retreatment file systems used were, D race retreatment files (FKG, Dentaire, Switzerland) DR1 30/10\% 15 mm length, DR2 25/4\% $25 \mathrm{~mm}$ in length. Speed and torque were set at $600 \mathrm{rpm}$ and $1.5 \mathrm{Ncm}$ respectively for continuous rotary motion.

ProTaper universal retreatment files (Dentsply International Inc., United States of America) D1 30/10\% 16 mm length, D2 25/8\% 18 mm length, D3 20/7\% 22 mm in length. Speed and torque were set at $300 \mathrm{rpm}$ and $5 \mathrm{Ncm}$ respectively for continuous rotary motion. ${ }^{13}$

TF adaptive files (Kerr Co., United States of America) SM1 20/4\% 25 mm length, SM2 25/6\% 25 mm length, SM3 $35 / 4 \% 25 \mathrm{~mm}$ in length. Speed and torque setting was set at $500 \mathrm{rpm}$ and $5 \mathrm{Ncm}$ according to manufacturer's instructions. TF adaptive files were selected for root canal filling removal, as a specific separate TF adaptive retreatment files were not available.

Retreatment files were evaluated under the operating microscope (magnification of $1.6 \mathrm{X}$ ) before the operation for any manufacturing defects. Each file system was used 
with continuous and TF adaptive motion. Thus each file system was used for a maximum of 30 teeth.

\section{Assessment of Retreatment Efficacy}

The time required for the files to reach working length was calculated time elapsed from the moment instruments estimate it touched the canal to till the instruments reached the working length. The time elapsed was estimated using a stopwatch. Complete removal of gutta-percha assessment was done by radiograph when no root canal filling material was seen adhering to the instrument or at the end of 4 minutes allotted for each retreatment system.

\section{Assessment of Instrument Deformation}

A number of cycles to deform or fracture in rotary motion, number of seconds for the instrument to deform or fracture, the sequence of instrument deformed or fractured, a segment of the instrument deformed or fractured were assessed. Instrument deformation was evaluated by inspecting the instrument after every use in the dental operating microscope (Labomed Prima, United States of America) at 2.5 X magnification. Deformation was confirmed when there is the presence of unwinding or any chipping of file edges.
Data were analyzed using ANOVA and Chi-square tests in SPSS version 23.0 (IBM Corp., United States of America)

\section{RESULTS}

Meantime taken for the different retreatment file systems with different rotary kinetic motions to reach working length is shown (Tables 1 to 3). There was no statistically significant difference between continuous rotary and TF adaptive motion for the time taken to reach the working length. However, there was a significant difference among the different retreatment file systems in the time taken to reach the working length with ProTaper universal retreatment files taking significantly less time compared to the other two systems. ProTaper universal retreatment files required less time than other file systems to reach the working length both in continuous rotary and TF adaptive motion.

Efficacy incomplete removal of gutta-percha from root canals is shown in Table 4. Chi-square statistical test showed a significant difference in gutta-percha removal among the three different file systems in continuous rotary motion; with ProTaper universal retreatment files being able to achieve complete removal of gutta-percha in more number of teeth compared to other two file

Table 1: Time taken (in secs) for the instrument to reach working length (ANOVA analysis showed significant difference $p-0.05$ )

\begin{tabular}{lllllll}
\hline File name & Mean & $N$ & Std. deviation & Minimum & Maximum & Significance \\
\hline D race & 51.0000 & 34 & 24.15057 & 20.00 & 95.00 & 0.000 \\
ProTaper & 28.5333 & 60 & 13.42343 & 11.00 & 60.00 & \\
TF adaptive & 52.2857 & 14 & 26.37369 & 29.00 & 91.00 & \\
\hline
\end{tabular}

Table 2: Time taken (in secs) to reach working length in the two different rotary motion evaluated (ANOVA analysis shows no significant difference)

\begin{tabular}{lllllll}
\hline Rotary motion & Mean & $N$ & Std. deviation & Minimum & Maximum & Signifiance \\
\hline Continuous rotary & 33.7667 & 60 & 16.80247 & 12.00 & 95.00 & 0.066 \\
TF adaptive motion & 44.8333 & 48 & 26.27226 & 11.00 & 91.00 & \\
\hline
\end{tabular}

Table 3: Time taken to reach working length different retreatment file system employed with two different rotary motion (ANOVA analysis shows no significant difference between different rotary motion)

\begin{tabular}{|c|c|c|c|c|c|}
\hline \multicolumn{6}{|c|}{ Report } \\
\hline \multicolumn{6}{|l|}{ WL time secs } \\
\hline File Name & Rotary motion & Mean & $N$ & Std. deviation & Significance \\
\hline \multirow[t]{3}{*}{ D race } & Continuous rotary & 41.5000 & 24 & 20.95667 & 0.066 \\
\hline & TF adaptive motion & 73.8000 & 10 & 14.30734 & \\
\hline & Total & 51.0000 & 34 & 24.15057 & \\
\hline \multirow[t]{3}{*}{ Protaper } & Continuous rotary & 25.8000 & 30 & 9.87927 & \\
\hline & TF adaptive motion & 31.2667 & 30 & 16.11329 & \\
\hline & Total & 28.5333 & 60 & 13.42343 & \\
\hline \multirow[t]{3}{*}{ TF adaptive } & Continuous rotary & 42.6667 & 6 & 6.42910 & \\
\hline & TF adaptive motion & 59.5000 & 8 & 34.66506 & \\
\hline & Total & 52.2857 & 14 & 26.37369 & \\
\hline \multirow[t]{3}{*}{ Total } & Continuous rotary & 33.7667 & 60 & 16.80247 & \\
\hline & TF adaptive motion & 44.8333 & 48 & 26.27226 & \\
\hline & Total & 38.6852 & 108 & 22.01871 & \\
\hline
\end{tabular}


Table 4: Efficacy of gutta-percha removal by different file systems used with two different kinetic motion (Chi-square statistical analysis was done)

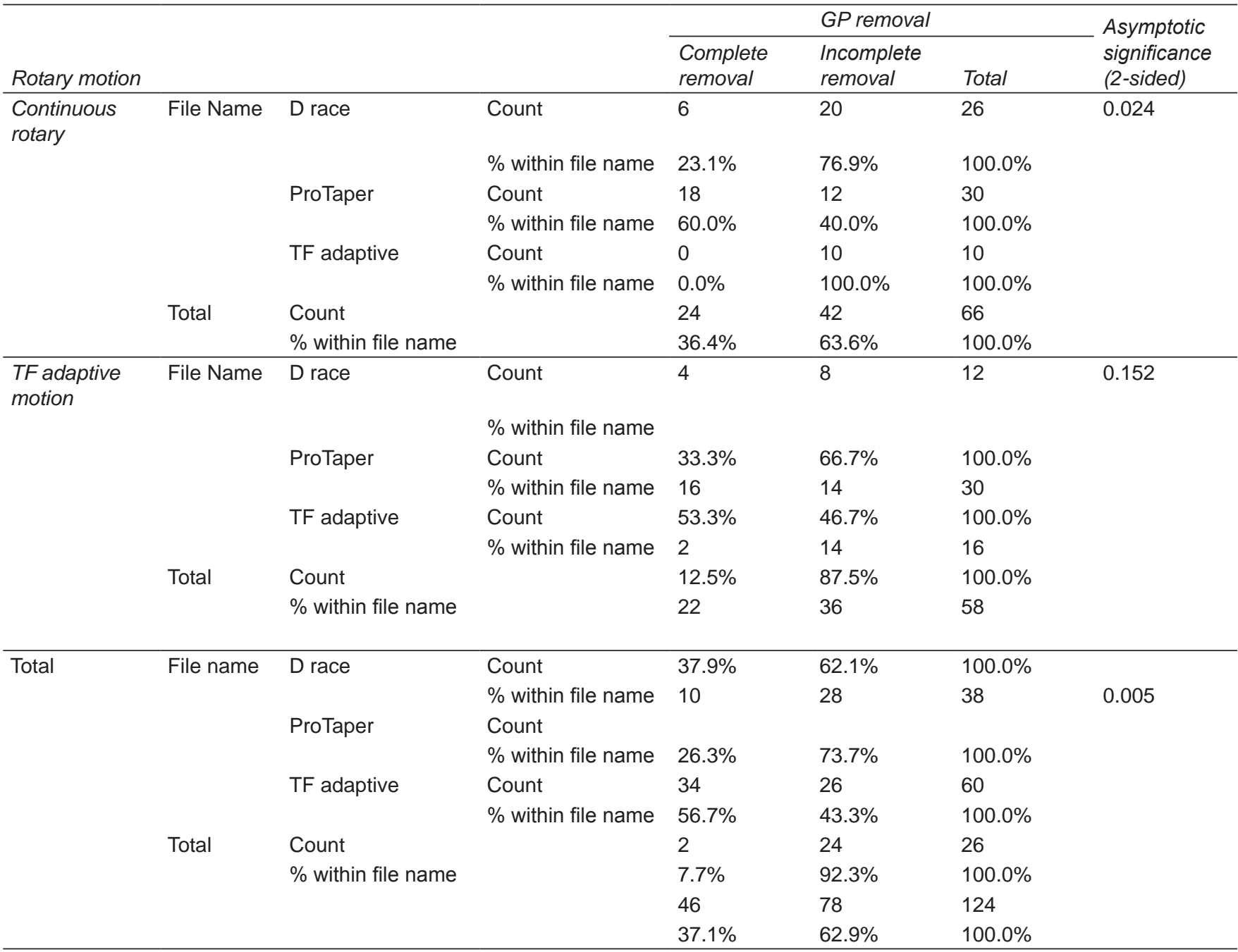

systems (Fig. 2A). In TF adaptive motion no significant difference was seen between different file systems in gutta-percha removal, but here also ProTaper universal retreatment files performed better than other two file systems. TF adaptive files which were not able to achieve complete removal of gutta-percha from any of the teeth in continuous rotary motion performed better with TF adaptive motion. Overall comparing all three retreatment file systems, ProTaper universal retreatment file system achieved complete removal of gutta-percha from more number of teeth (significant $\mathrm{p}<0.05$ ) (Figs $2 \mathrm{~B}$ and $\mathrm{C}$ ).

Both $D$ race retreatment and TF adaptive files had fracture incidence in this study (Figs 3 and 4). D race retreatment file fractured in 13th and 6th canal usages with continuous rotary and TF adaptive motion respectively, it was the second sequence file which fractured, and it was at the apical segment. TF adaptive file fractured in 5 th and 8th canal usages with continuous and rotary and TF adaptive motion respectively, it was first to sequence file which fractured at the apical segment (Fig. 4). Instrument deformation occurred in all three retreatment file systems, D race file system started deforming with second canal usage and it was the second sequence file which deformed in both continuous and TF adaptive
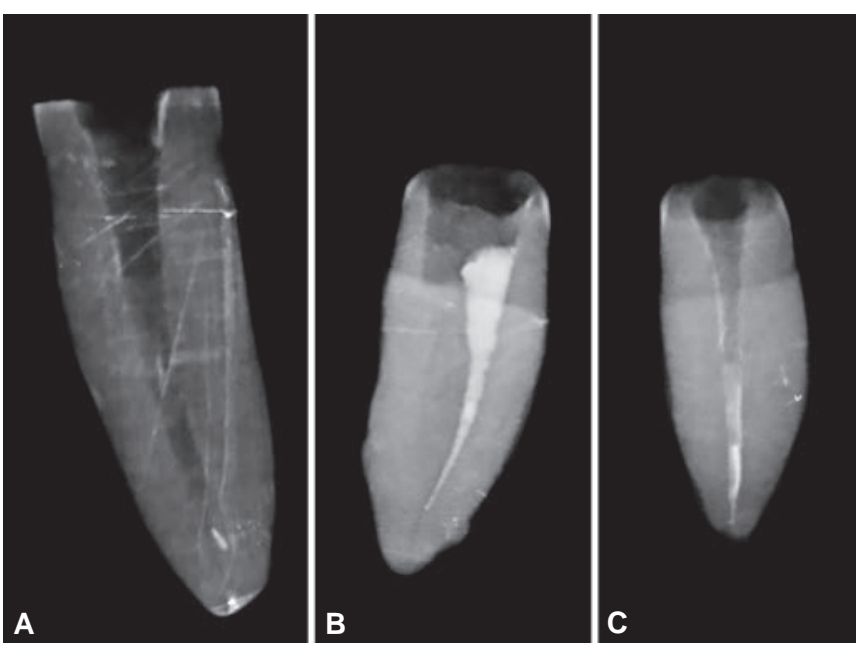

Fig. 2A to C: (A) Radiograph of complete removal of gutta-percha from the canal by ProTaper universal retreatmentfiles; (B) and (C) Radiograph of incomplete removal of gutta-percha by $D$ race and TF adaptive file systems 
motion (Fig. 5). A segment of deformation occurrence was in apical third and multiple areas along the length of the instrument in continuous and TF adaptive motion respectively. ProTaper universal retreatment file system deformation occurred with third and fifth canal usages in continuous and TF adaptive motion respectively (Fig. 6). It was the third middle segment in second and first sequence files which deformed in continuous and TF adaptive motion respectively. TF adaptive file had deformation occurrence in second and first canal usage in the apical segment with continuous and TF adaptive motion respectively. The sequence of the TF adaptive file system to deform was multiple files in both types of kinetic motion used.

Time took and the number of cycles for the files to deform is presented in Table 5. About the number of seconds taken for the different file systems to deform it was seen the ProTaper universal retreatment files resisted deformation for the maximum amount of time compared to other file systems in both continuous (780 seconds) and TF adaptive motion (1269 seconds). Both ProTaper universal and D race retreatment file system time taken to deform increased with TF adaptive motion compared to a continuous rotary motion. Whereas with TF adaptive file system time taken to deform decreased with TF adaptive motion compared to a continuous rotary motion. The number of cycles taken to deform in continuous rotary motion, it was observed that ProTaper files deformed at an earlier stage (3900 cycles) compared to other files. TF adaptive and D race files deformed at 4400 and 4100 cycles respectively. D race retreatment files in continuous rotary motion fractured at 23700 cycles and 2824 seconds and in TF adaptive motion at 1889 seconds. TF adaptive files in continuous
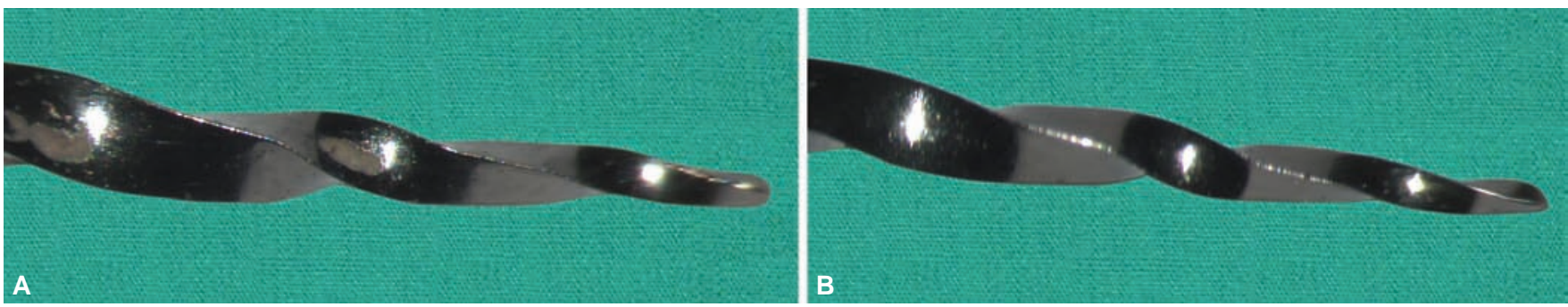

Figs 3A and 3B: (A) Fractured $D$ race retreatment file in continuous rotary motion and

(B) Fractured $D$ race retreatment file in TF adaptive motion. (Magnification $2.5 \mathrm{x}$ )
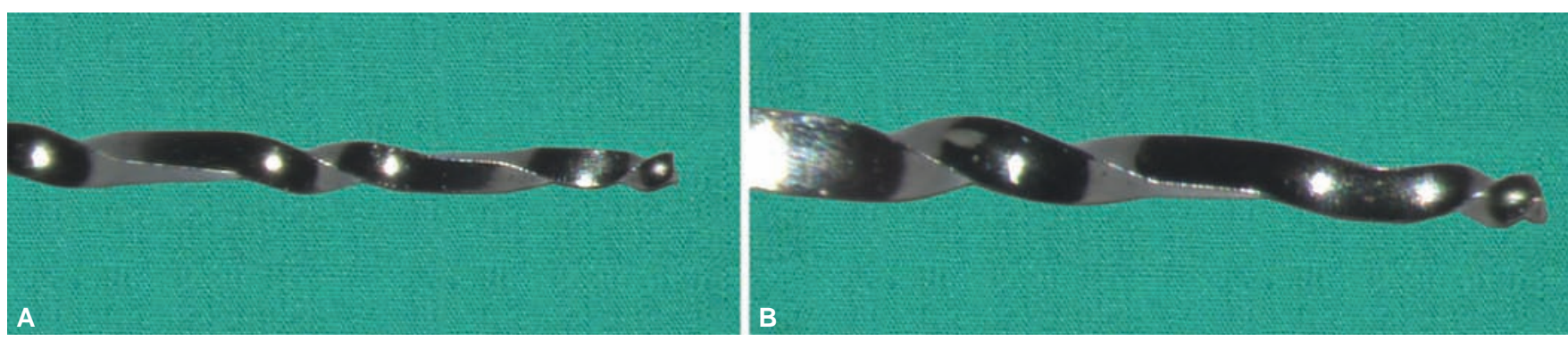

Figs 4A and 4B: (A.) Fractured TF adaptive file in continuous rotary motion and

(B) Fractured $\mathrm{D}$ race retreatment file in TF adaptive motion. (Magnification $2.5 \mathrm{x}$ )
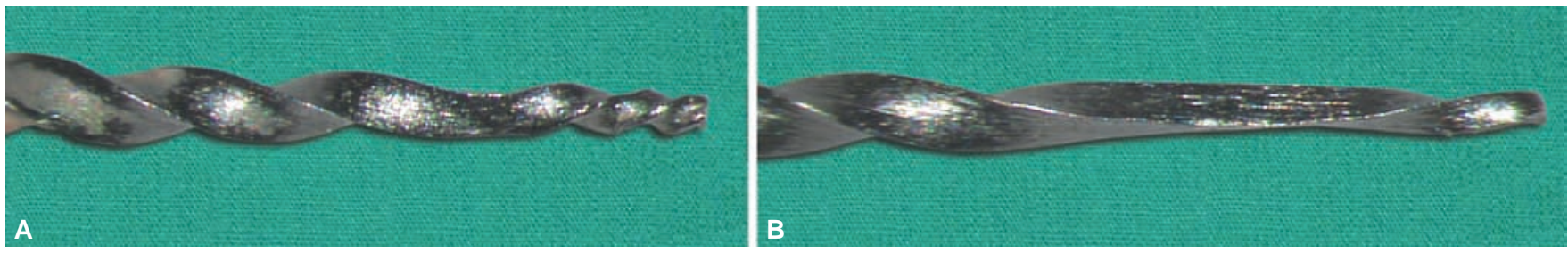

Figs 5A and 5B: Deformed D race treatment files in continuous rotary motion and TF adaptive motion respectively. (Magnification $2.5 \mathrm{x}$ )

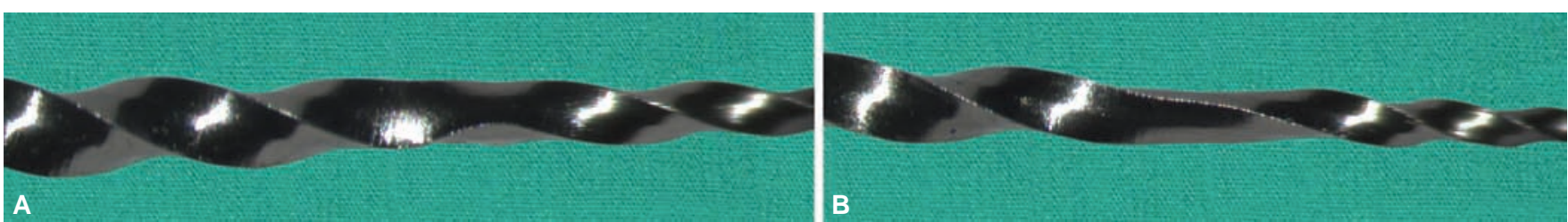

Figs 6A and 6B: ProTaper retreatment files deformation in continuous rotary and TF adaptive motion respectively. (Magnification $2.5 \mathrm{x}$ ) 
Table 5: Number of seconds and cycles to deform the instrument. Number of cycles is given in parenthesis

\begin{tabular}{|c|c|c|c|c|}
\hline Rotary motion & & & $\begin{array}{l}\text { Number of seconds (number of } \\
\text { cycles) for the instrument to deform }\end{array}$ & $\begin{array}{l}\text { Instrument fracture (number of } \\
\text { seconds) (number of cycles) }\end{array}$ \\
\hline \multirow[t]{3}{*}{ Continuous rotary } & File name & $D$ race & $482(4100)$ & Yes (2824 secs) (23700 cycles) \\
\hline & & ProTaper & $780(3900)$ & Nil \\
\hline & & TF adaptive & $488(4400)$ & Yes (1326 secs) (11050 cycles) \\
\hline \multirow[t]{3}{*}{ TF adaptive motion } & File name & $\mathrm{D}$ race & 609 & Yes (1889 secs) \\
\hline & & ProTaper & 1269 & Nil \\
\hline & & TF adaptive & 269 & Yes (2158 secs) \\
\hline
\end{tabular}

motion fractured at 11050 cycles and 1326 seconds and in TF adaptive motion at 2158 seconds.

\section{DISCUSSION}

One of the main objectives of root canal retreatment is complete removal of the root canal filling material and reaching the working length. By achieving removal of as much of root canal filling material as possible the clinician will be able to disinfect the canal in a better way to obtain success in the retreatment procedure. ${ }^{8}$ The present study aimed to evaluate and compare the efficacy of currently available retreatment file systems in removing the guttapercha and instruments fatigue resistance while removing the filling material to the newly introduced TF adaptive files in continuous rotary and TF adaptive motion. In the present study extracted lower premolars with straight canals were used this was done to simplify the process of standardization. ${ }^{8}$

The results of the present study show that there is no significant difference in time taken for the instruments to reach a working length between continuous and $\mathrm{TF}$ adaptive motion, and infact TF adaptive motion (44 secs) required more time than continuous rotary motion ( 33 secs) to reach working length. Among the three retreatment instruments evaluated ProTaper universal retreatment files required significantly least time to remove gutta-percha compared to other files in both continuous and TF adaptive motion. Thus the null hypotheses regarding the time taken for the files to reach working length were partially rejected. The results of this study that ProTaper universal retreatment files taking least time and TF adaptive files taking more time than compared to other files to reach working length is in accordance to a previous study with TF adaptive files for retreatment, ${ }^{13}$ and in agreement with the result of another report where TF adaptive motion required more time for retreatment compared to continuous motion. ${ }^{14}$

In this study, no solvent was used, or any attempt to establish Glyde path was made as we did not want these procedures to influence the ability of the files to reach working length or removal of the filling material. Analyzing the results of the ability of the instruments to completely remove gutta-percha reveals ProTaper universal retreatment system performed significantly better than other file systems. Only ProTaper universal retreatment files were able to remove gutta-percha from more than $50 \%$ of samples completely. ProTaper universal retreatment files ability to completely remove filling material decreased in TF adaptive motion compared to the continuous rotary motion. TF adaptive files in comparison with other files performed significantly poorly with only $7.7 \%$ of samples able to be completely removed from the filling material. TF adaptive files performed better with TF adaptive motion in achieving complete removal of gutta-percha from $12.5 \%$ of samples; whereas with continuous rotary motion it was not able to completely remove gutta-percha from any of the samples. This could be because these files are manufactured for primary root canal treatment and have a passive non-cutting tip, whereas retreatment files tip is active cutting to aid in root canal filling removal. ${ }^{15,16}$ ProTaper universal retreatment files performing better than other retreatment files in this study is per an earlier report. ${ }^{13}$ In another study where ProTaper universal retreatment files were used in continuous rotary and TF adaptive motion and were reported that TF adaptive motion was able to remove more filling material. ${ }^{14}$ This variation in result might be because of the methodology employed, with samples in the cited study being mandibular molar mesiobuccal canal and also the canal preparation was completed with ProTaper universal system and retreatment was done with same manufacturers ProTaper universal retreatment files. Whereas in our study, canal preparation was done with Mtwo files and retreatment was completed with file system from different manufacturers. The objective of employing different file system for canal preparation and retreatment procedure was we did not want a design of the canal preparation file system to influence the efficacy of the retreatment files. Also in clinical scenario seldom will clinician know what system was employed for root canal preparation in failed cases. These reasons necessitated that canal preparation be done with a file system that was not from a manufacturer whose retreatment files we are investigating. The superiority of ProTaper universal retreatment files 
concerning time taken to reach working length and complete removal of root canal filling material in this study is in agreement with previous reports. ${ }^{3,17}$ ProTaper files improved performance about gutta-percha removal has been attributed to its increased taper of $7 \%$ compared to $4 \%$ taper in the other file systems used in this study and also because of the convex triangular cross-section aiding in better heating of gutta-percha and its eventual removal from the canal. ${ }^{16,17}$

TF adaptive motion proposes to combine the advantages of both continuous rotary and reciprocating motion. ${ }^{14}$ The speed of the instruments may be reduced due to the change in reciprocating angle especially in retreatment procedure because of increased canal stress. ${ }^{9}$ Most of the rotary files available in the market are designed for cutting in $\mathrm{CW}$ direction; thus most root canal rotary files can be used with TF adaptive motion. ${ }^{9}$ One of the main proposed advantages with TF adaptive motion it increases the life of the instrument with increased time to fracture under cyclic fatigue. ${ }^{11}$ But only minimal data is available whether TF adaptive motion improves the fatigue resistance of retreatment files. Two studies evaluated the cyclic fatigue of retreatment files in TF adaptive motion and concluded that TF adaptive motion increased the number of cycles to fracture compared to the continuous rotary motion. $12,18,19$ Rotation per minute (rpm) for TF adaptive motion was calculated by two different methodologies in both these studies. Also, canal lubricant was used in these investigations which were not the case in this investigation. Rotation per minute reported in these two reports was $400 \mathrm{rpm}$ and $500 \mathrm{rpm}$ respectively. With either $400 \mathrm{rpm}$ or $500 \mathrm{rpm}$, it was seen that both $D$ race and ProTaper universal retreatment files had increased cycles to deform with TF adaptive motion, whereas other TF adaptive file system had decreased cycles to deform. Studies pertaining to torsional fatigue resistance with TF adaptive motion for retreatment files are not available, and as most of these files are likely to experience torsional stress in removing gutta-percha more information on this aspect is needed. ${ }^{12}$ All the files in this study except TF files had deformation at a later time with TF adaptive motion compared to continuous rotary motion. This could be because of slowing down of speed with TF adaptive motion compared to continuous motion as earlier mentioned. ${ }^{9} \mathrm{D}$ race retreatment and TF adaptive files in this study had a fracture in both types of motion. $D$ race file in TF adaptive motion fracture occurred earlier than compared to continuous rotary motion, whereas TF adaptive file resisted fracture for more amount of time with TF adaptive motion. The fracture occurrence in continuous rotary motion with $\mathrm{D}$ race could be because of higher speed $(600 \mathrm{rpm})$ and lower torque setting $(1.5 \mathrm{Ncm})$ recommended by the manufacturer than compared to other file systems as reports on rotational speed and torque setting have shown that instrument life is extended by having a lower rpm and higher torque setting. ${ }^{20-22}$ But the results of this study contradict with an earlier report where $\mathrm{D}$ race retreatment file had better cyclic fatigue than compared to ProTaper universal retreatment files in the canal with a $60^{\circ}$ angle of curvature. ${ }^{23}$ This difference could be because of the variation in study methodology as files were used in the artificial canal without any filling material. Also, canals were curved unlike in the current study where the canals were straight, and files were used with different speed, torque setting and also not tested for the torsional type of stress. ${ }^{23}$ Fracture of TF adaptive file could be because the design of the file is not meant for retreatment, but with TF adaptive motion there was an increase in time required for the file to fracture supporting the claim that the TF adaptive motion improves the resistance of the file to fracture. ${ }^{11}$ Therefore null hypotheses that there will be no difference between two different kinetic motions in improving the resistance of retreatment files to deformation or fracture is partially rejected. In both TF adaptive and continuous rotary motion, ProTaper universal files had resisted deformation for more amount of time than compared to other file systems. This could be because of lower speed and higher torque setting used in this study. Since ProTaper retreatment and primary treatment files had been extensively studied, and reports of using this instrument at higher torque had improved the performance; a higher torque setting and lower rpm was used for this instrument in this study. ${ }^{13,21,22}$ Further studies are required to explore about the influence of TF adaptive motion concerning improving the torsional fatigue resistance of retreatment files.

\section{CONCLUSION}

Within the limitations of this study, ProTaper universal retreatment files required the least time to reach working length and were better in deleting the gutta-percha from the root canal than compared to D race retreatment and TF adaptive files.

No advantage was found with TF adaptive motion either in the time taken for files to reach the working length or in their ability to completely remove guttapercha from root canals.

ProTaper universal retreatment files resisted deformation better than compared to other file systems. TF adaptive motion helped both $\mathrm{D}$ race and ProTaper retreatment files by increasing the time taken to deform.

Only ProTaper retreatment files in this study were able to resist fracture in both continuous rotary and TF adaptive motions.

TF adaptive motion did not improve the performance of the retreatment files in this study. 


\section{REFERENCES}

1. Takahashi CM, Cunha RS, de Martin AS, Fontana CE, Silveira $\mathrm{CF}$, da Silveira Bueno CE. In vitro evaluation of the effectiveness of ProTaper universal rotary retreatment system for gutta-percha removal with or without a solvent. J Endod 2009 Nov;35(11):1580-1583.

2. Gluskin AH, Peters CI, Wong RDM, Ruddle CJ. Retreatment of non-healing endodontic therapy and management of mishaps. In. Ingle JI, Bakland LF, Baumgartner JC (Eds). Ingle's Endodontics. Sixth edition. BC Decker Inc, Hamilton. USA. 2008.1088-1161.

3. Gu LS, Ling JQ, Wei X, Huang XY. Effcacy of ProTaper Universal rotary retreatment system for gutta-percha removal from root canals. Int Endod J 2008 Apr;41(4):288-295.

4. Imura N, Kato AS, Hata GI, Uemura M, Toda T, Weine F. A comparison of the relative efficacies of four hand and rotary instrumentation techniques during endodontic retreatment. Int Endod J 2000 Jul;33(4):361-366.

5. Rödig T, Kupis J, Konietschke F, Dullin C, Drebenstedt S, Hulsmann M. Comparison of hand and rotary instrumentation for removing gutta-percha from previously treated curved root canals: a microcomputed tomography study. Int Endod J 2014 Feb;47(2):173-182.

6. Sae-Lim V, Rajamanickam I, Lim BK, Lee HL. Effectiveness of ProFile .04 taper rotary instruments in endodontic retreatment. J Endod 2000 Feb;26(2):100-104

7. Schirrmeister JF, Wrbas KT, Schneider FH, Altenburger MJ, Hellwig E. Effectiveness of a hand file and three nickel titanium rotary instruments for removing gutta-percha in curved root canals during retreatment. Oral Surg Oral Med Oral Pathol Oral Radiol Endod 2006 Apr;101(4):542-547.

8. Zuolo AS, Mello JE Jr, Cunha RS, Zuolo ML, Bueno CE. Effcacy of reciprocating and rotary techniques for removing filling material during root canal retreatment. Int Endod J 2013 Oct; 46(10):947-953.

9. Çapar ID, Arslan H. A review of instrumentation kinematics of engine-driven nickel-titanium instruments. Int Endod J. 2016 Feb;49(2):119-135.

10. Yared G. Canal preparation using only one Ni-Ti rotary instrument: preliminary observations. Int Endod J. 2008 Apr;41(4): 339-344.

11. Gambarini G, Glassman G. In vitro analysis of efficiency and safety of a new motion for endodontic instrumentation:TF adaptive. Roots. 2013; 3,12-15.

12. Özyürek T, Koray Yılmaz, Gülşah Uslu. Effect of adaptive motion on cyclic fatigue resistance of a nickel titanium instru- ment designed for retreatment. Restor Dent Endod. 2017 Feb; 42(1):34-38

13. Akbulut MB, Akman M, Terlemez A, Magat G, Sener S, Shetty H. Efficacy of Twisted File Adaptive, Reciproc and ProTaper Universal Retreatment instruments for root-canal-filling removal: A cone-beam computed tomography study. Dent Mater J. 2016;35:126-131.

14. Capar ID, Arslan H, Ertas H, Gök T, Saygılı G. Effectiveness of ProTaper Universal retreatment instruments used with rotary or reciprocating adaptive motion in the removal of root canal filling material. Int Endod J. 2015 Jan;48(1):79-83.

15. Peters OA, Paque F. Current developments in rotary root canal instrument technology and clinical use: a review. Quintessence Int. 2010 Jun;41(6):479-488.

16. Marques da Silva B, Baratto-Filho F, Leonardi DP, Henrique Borges A, Volpato L, Branco Barletta F. Effectiveness of ProTaper, $\mathrm{D}-\mathrm{RaCe}$, and Mtwo retreatment files with and without supplementary instruments in the removal of root canal filling material. Int Endod J. 2012 Oct;45(10):927-932.

17. Bramante CM, Fidelis NS, Assumpção TS, Bernardineli N, Garcia RB, Bramante AS, de Moraes IG. Heat release, time required, and cleaning ability of MTwo R and ProTaper universal retreatment systems in the removal of filling material. J Endod. 2010 Nov;36(11):1870-1873.

18. Özyürek T, Yılmaz K, Uslu G. Effect of adaptive motion on cyclic fatigue resistance of R-Endo nickel-titanium file. Saudi Endodontic Journal. 2017;7:82-86

19. Higuera O, Plotino G, Tocci L, Carrillo G, Gambarini G, Jaramillo DE. Cyclic fatigue resistance of 3 different nickeltitanium reciprocating instruments in artificial canals. J Endod. 2015 Jun;41(6):913-915.

20. Inan $U$, Aydin C. Comparison of cyclic fatigue resistance of three different rotary nickel-titanium instruments designed for retreatment. J Endod. 2012 Jan;38(1):108-111.

21. Berutti E, Negro AR, Lendini M, Pasqualini D. Influence of manual preflaring and torque on the failure rate of ProTaper rotary instruments. J Endod. 2004 Apr;30(4):228-230.

22. Lopes HP, Ferreira AA, Elias CN, Moreira EJ, de Oliveira JC, Siqueira JF Jr. Influence of rotational speed on the cyclic fatigue of rotary nickel-titanium endodontic instruments. J Endod. 2009 Jul;35(7):1013-1036.

23. Topçuoğlu HS, Topçuoğlu G, Aktı A. Comparative evaluation of cyclic fatigue resistance of D-RaCe and ProTaper retreatment instruments in curved artificial canals. Int Endod J. 2016 Jun;49(6):604-609. 